\title{
Project Based Learning Activities in Engineering Education
}

\author{
http://dx.doi.org/10.3991/ijep.v3iS2.2438 \\ Tiago Andrade \\ LAETA - Associate Laboratory for Energy, Transport and Aeronautics \\ Universidade do Porto, Porto, Portugal
}

\begin{abstract}
In the present work, the author reports examples of his involvement in different teaching/learning methodologies during his five years of the Integrated Master Degree in Mechanical Engineering at the Faculty of Engineering of University of Porto. The aim is to explain how useful those experiences have been, allowing him to explore many techno-scientific activities within his engineering education while student as well as other transferable skills and later, up to the present, as a professional in academic environment. The author wishes to underline the excellent opportunity he had to practice reflection processes as an essential methodology of his engineering education.
\end{abstract}

Index Terms-project based learning; reflection process; mentoring; transferable skills; engineering education; multidisciplinary projects.

\section{INTRODUCTION}

The author studied for his degree in Mechanical Engineering at the Faculty of Engineering of University of Porto (FEUP) between academic years 2002/03 and 2007/08.

Before the new Bologna curriculum was officially implemented at FEUP in 2006/07, our school was already following ABET and EUR-ACE recommendations [1, 2] since at least the author's first academic year, offering in addition to traditional teaching/learning practices other methodologies based on project based mentoring activities. In 2003, a project named Exploring Multidisciplinary Engineering Problems (EMPE) started, in a voluntary base, a momentum between teachers/researchers, students and technicians involving all departments at FEUP and even extended actions to other Faculties at University of Porto (UPorto) as well as to other Universities in Portugal, [3, 4].

In 2004 two new initiatives appeared. One, named PESC projects - "To Design, to Venture, to Know and to Materialize" and other called iJUP program - Young Research at University of Porto.

Another exciting opportunity was the STRAPLEX workshop (STRAtospheric PLatform EXperiment) [5], held at the ESA Technology and Research Centre.

All those experiences which will be briefly described in the next sections have proved to the author the relevance of teaching/learning mentoring methodologies he experienced as a student, learning or even "teaching", the latter being the case related with his indirect later involvement in younger students' work.
Another relevant output from these experiences was the fantastic opportunity for balancing the increasing specialization in today's engineering curricula and the ensuing fragmentation of subjects which lead to a growing need for unification of concepts. In this way project based teaching/learning mentoring methodologies help to smooth student's difficulty in getting a global picture of subjects and so improving knowledge and understanding. Working with multidisciplinary open problems since his very beginning as engineering student, as are those used in project based learning approaches, the author experienced the integration of knowledge as a natural task and perceived realistic constraints of everyday life when looking for the key aspects of a problem. In those processes he was compelled to train creativity, to become an active participant and to get a deeper understanding of basic physical and mathematical concepts by facing them “in action”, in accordance with Kolb's theory of experiential learning [6, 7]. And added benefits were also provided by these practices as fantastic opportunities for a cooperative learning/teaching/researching/developing and/or innovation practice, becoming highly motivating, creative and stimulating for both students and teachers and understanding the role of each one as a society member for the engineering sustainability.

So the experience of team work as a student and in his final year a closer connection to research team elements that intensively practiced those approaches encouraged the author to join that specific research group under a postgraduate grant. And later, he carried on the activity as a research technician in a National Associate Laboratory, where he has been involved in diversified studies and developments within the same research group, using most of the knowledge and specially putting in action the engineering analysis, the engineering design, the investigation procedures, the engineering practice, the constant and clear need for lifelong learning as well as transferable skills. So, in a natural context as the one of his present professional involvement the author has been facing not only his everyday environment but also in many other different contexts, crossing with many researchers from different fields of research activities, innovation actions, industrial contexts and technoscientific meetings.

The author also learned to appreciate the fantastic opportunity of meeting people moved by curiosity, interest in knowledge and in learning new subjects, with many different backgrounds, different cultures and experiences and available to share information and results and to cooperate in innovative methods for solving problems. 
In the next section the author will describe various multidisciplinary projects from different programs available at FEUP, UPorto and ESA. Further to the short descriptions of the projects main goals some comments will be added about important aspects from those experiences still in the back of the author's mind.

\section{WHILE FRESHMAN STUDENT}

In 2004, as a mechanical engineering degree student at FEUP, the author entered a PESC program (in its first edition - PESC1). This program has been implemented based in Bologna recommendations and was running simultaneously with normal academic activities in a voluntary base. The main goal of this program was to promote engineering activities in which students from different areas and from different academic years would work in a team framework. Two teachers, one being the responsible, were the proponents of each project proposal and assisted the students' team in a mentoring base. The projects were previously publicized and students would express their interest in up to 3 topics according to their preferences. In this context the author engaged a project in remote controlled models during the first two consecutive editions of program PESC (PESC1 and PESC2, in the academic years 2004/05 and 2005/06).

First, at PESC1, a car model velocity control system based in an electro-mechanical solution had to be improved by replacing that system by one of electronic type. The remote prototype was also sensorized by including ultrasonic and light sensors (PESC1).

Later, at PESC2, a robot arm was designed and controlled, Fig. 1. This experience allowed the author to contact with his teachers in a different base than that in traditional classes, and offered him the capability of discussing solutions and doubts with teachers and colleagues in a team framework. These two experiences have been very enthusiastic mainly because he was free to find solutions, often making mistakes and so he got the great opportunity of learning with them. And, in this process the author had a long way to go in finding, guessing, studying, getting the problem key and gathering information about solutions for solving each specific problem. In fact, this was great because the author was normally impressed and shocked by the fact that in traditional engineering teaching students usually have to solve problems and get the correct solution! In engineering activity all problems have several solutions, some better than others, and one being the most convenient for each project specific requirements. These activities during the first years of the author's degree have helped to overcome many of the freshman subjects related with mathematics and conceptual knowledge and turned possible to understand engineering in a much more realistic way than by solving only theoretical problems using paper and pencil.

This also provided the conditions to correlate many traditional problems with real problems. In relation to the students within the team framework the author became able to understand the differences between team elements (normally in groups of up to 6 elements), how to work as a team by distributing tasks, how to get the most from each other and how to solve conflicts.

Also, the concept of individual responsibility as a member of the team in charge of one task was very well perceived. This was also a great opportunity to understand and judge the author's own capabilities and limitations in order to overcome many of them and then widen his knowledge and abilities. One important aspect was related with the need for finding specific information - technical data sheets and manuals - and to learn from them how to select components and parts and with them to understand material characteristics. All of this had to be also integrated with the solution costs which were and are always a must in engineering practice and were exercising the process-reflection.

\section{While StUdent Under Bologna Process}

In the academic year 2006/07 the author was involved in a STRAPLEX project and its workshop (STRAtospheric PLatform EXperiment) [5], held at the ESA Technology and Research Centre (ESTEC) in Noordwijk, Netherlands, June 25-26, 2007, Fig. 2. The control of the "Straplex module" rotation around its central axis during its upward moving phase by using a new type of electrostatic control device was the project objective.

This has been a great opportunity for the author providing him collaboration and contact with a top technology agency. He visited some of the agency structures such as the hangar where a satellite would be released in a few days' time, the anechoic chamber, the museum with old satellites and other technologies like some labs.

This visit gave the author the opportunity to contact with some senior engineers and to get the perception of team task management. Also, it was a good opportunity for understanding the relevance of sharing multicultural knowledge and for facing different backgrounds linked by a common interest.

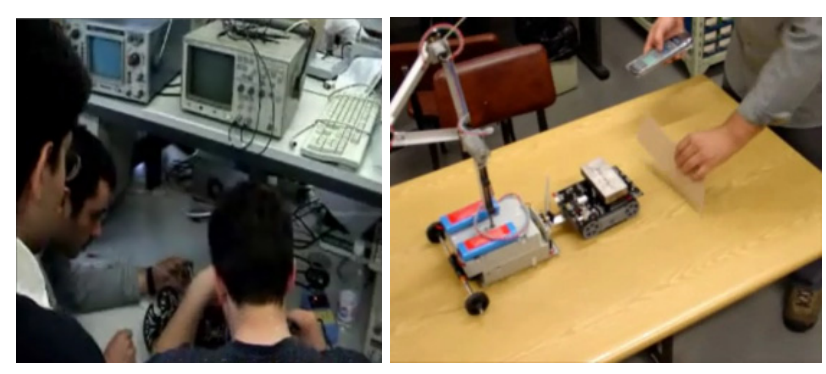

Figure 1. Car remote control and Robotic arm in PESC1 and PESC2 project

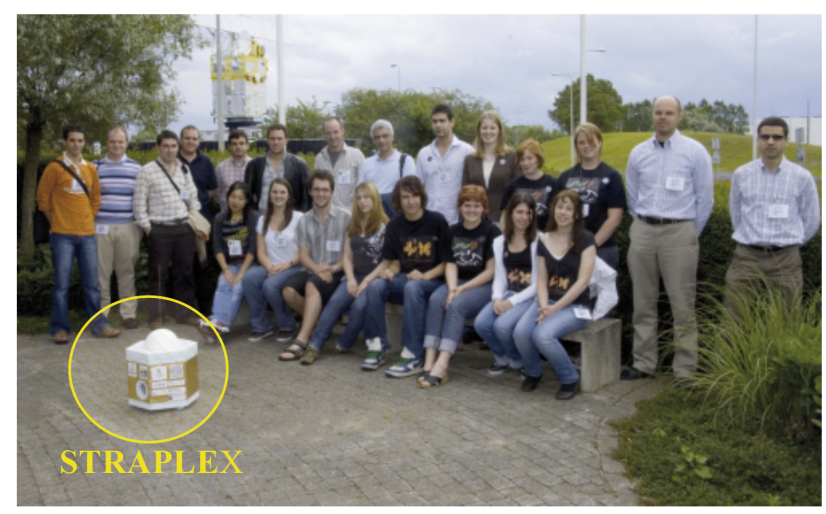

Figure 2. STRAPLEX workshop participants, Noordwijk, Netherlands 


\section{A. Final year student}

In 2008 the author engaged a multidisciplinary project team for "Development of a Handgrip Dynamometer for Nutritional Assessment”, within the Young Research at University of Porto Program. The main objective of this project was the mechanical design of a new device for evaluating hand grip strength and later its sensorization and data processing system, Fig. 3.

The multidisciplinary team engaged teachers/researchers from different schools and departments (Faculty of Engineering and Faculty of Nutrition and Food Sciences), the collaboration of a Portuguese Metrological Laboratory for Industrial Calibration and Measurement (CATIM) and students from nutrition as well as mechanical and electrical engineering areas. The project based mentoring approach, the work multidisciplinary aspects, the practice and development of teamwork skills and the successful final prototype reached, Fig. 3, had incentived and engaged, all together, the author interest during his final year of the Integrated Master in Mechanical Engineering at FEUP.

All the described projects (PESC1 and 2, Straplex and Young Research at University of Porto Program) had fostered the author's reflection process, maturity, responsibility and transferable skills, as essential aspects to perform or collaborate in ongoing work or final reports. The author also had his first opportunity for collaborating in a techno-scientific article [8] submitted to the International iJUP 2009 meeting. In this meeting of more than 700 participants, the author was in contact with Brazilian students and teachers, and also with students and teachers from all faculties of Porto University and form ERASMUS Mobility programs, by getting in touch with so many distinct projects from all knowledge areas. In fact, it has been important to understand that architecture, humanities, medicine, sports and arts are areas where engineering needs to be present. This experience contributed again for broadening the author's perspectives, flexibility to new ideas and creativity. At the present the author still finds contributions from all these aspects for his everyday activity within R\&D\&I.

\section{B. Integrated Master Thesis}

Simultaneously, the author started his Integrated Master Thesis in the second semester of that academic year (2007/08). He developed a project named "Digital underbed scale system" comprising mechanical, sensorization and electronic designs and even the sensorization and electronic systems implementation. Those tasks were carried out within activities going on in the same research team.

This project was again a very interesting work and all the experience accumulated from past multidisciplinary projects described above was the main reason for the success of this particular task even in the very short period of time of one semester, Fig. 4, [9].

The continuing integration in related works within the UISPA team (UISPA-System Integration and Process Automation Research Unit) within the Associate Laboratory LAETA (funded by Portuguese Science Foundation) helped the author to understand the different researchers' roles within a team, from those oriented for new technological aspects to the ones engaged with project organization, coordination and overall integration of activities and for the group discussions in major project decisions.

\section{While a GRAdUATE STUdENT}

The experience of a "healthy" and proactive environment within the research team during all these works led the author to apply for a grant in the framework of the team Research Unit, after finishing his degree. So, in January 2009 he received a grant from UISPA, for continuing work in device developments for health and nutrition areas. Inevitably, for dealing with those new areas, the experience coming from multidisciplinary project teams was an important acquired trained skill. The ability for understanding different needs and perspectives and for expecting diverse contributions has been essential for the projects briefly described below.

\section{A. Engaging innovative activities}

By then he engaged the ongoing work of a new project in the same line, but now for evaluating \% of body fat (\%BF). The objective was to develop a system for evaluating the \%BF based in the design of a novel mechanical structure and of a dedicated virtual instrument. Finally, a wireless communication system between them was also designed and developed. In July 2010, the author became a member of the Associate Laboratory LAETA, where the research Unit UISPA is integrated.

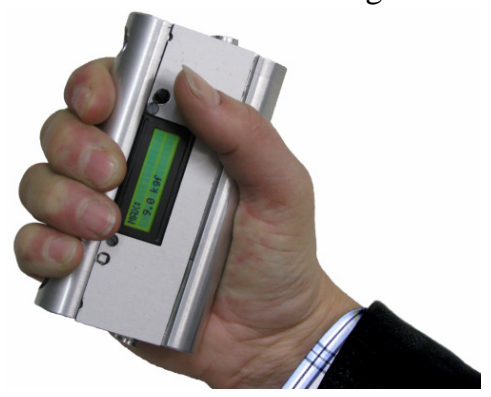

Figure 3. Small, accurate, digital, auto-ranging and light Handgrip

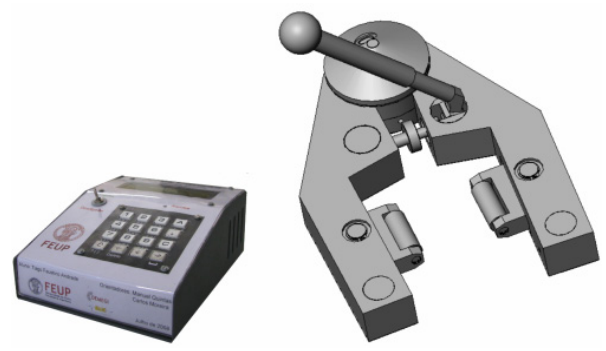

Figure 4. Digital under-bed scale system

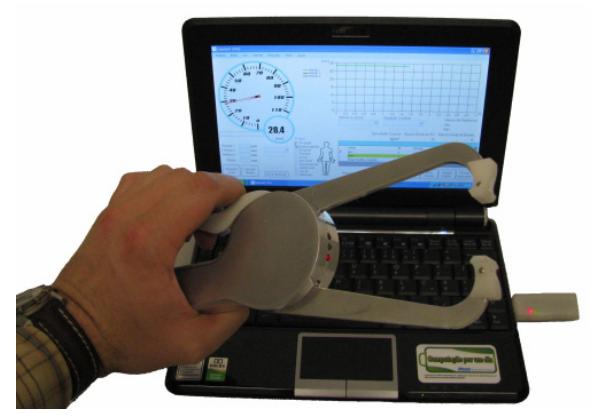

Figure 5. LipoTool - the integrated system 


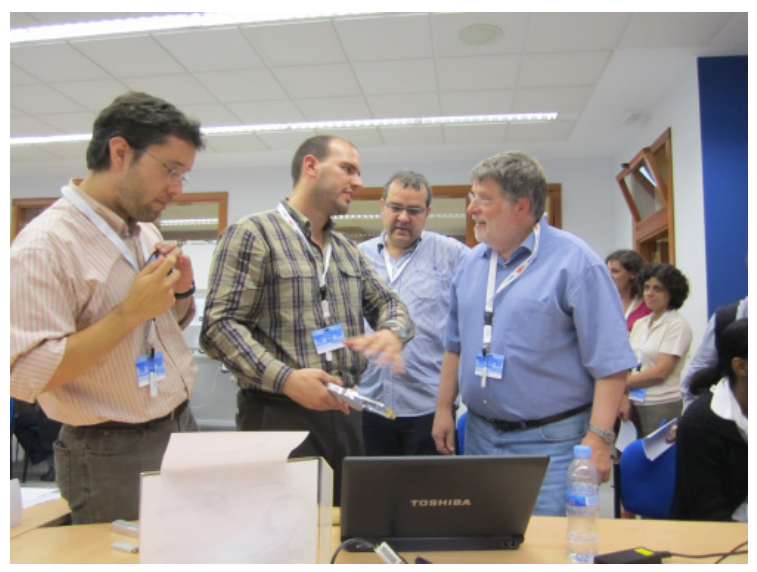

Figure 6. LipoTool - REV2012 Exhibition Session

Since then the author has been working in the development of the LipoTool system, Fig. 5, collaborating in two already submitted patents now pending (one national and another international, [4-5]), participating actively in the market evaluation, collaborating in the submissions of LipoTool to two awards recently achieved, also co-authoring several communications in conferences [10-20], where he has represented the team. Six LipoTool systems have been sold and are now working in research centers/units/institutions. Here, he has been acting as one of the bridge elements between the new system users.

The author has been the team member recently at the International Geneva Exhibition where he presented the LipoTool system (http://ipotool.com), and also he has been the only Portuguese participant. The system was awarded with a Silver medal at the $40^{\text {th }}$ International Exhibition of Inventions of Geneva, April 18-22, 2012, Switzerland.

In July, at the REV 2012 Exhibition Session, Duesto, Bilbao, Spain, a demo of LipoTool was presented integrated in topics like: Measurement Technology, Remote Control and Virtual Instrumentation and got a successful engagement of participants, Fig. 6.

\section{B. Online engineering - online labs and development and control of sensors network}

During the last year the author has also been responsible for the maintenance of online labs FEUP, since the institutional support has been interrupted. He has been helping students to overcome technical difficulties, contributing for keeping the interest and usefulness of those learning materials.

In this area the author was involved in the event exp.at'11, November 2011, a conference devoted to online experimentation, and in that particular edition to Remote and Virtual Labs (RVLs). exp.at'11 was held at the Calouste Gulbenkian Foundation in November 2011 where the author, as local arrangement committee member, and divided between the conference and a remote maintenance of online labs FEUP, managed to guarantee all the technical operational conditions for the success of the first edition of an Exhibition Session for RVLs demos from some participants devoted to all participants.

At present the author is involved in studying and developing network systems for sensors and actuators using microcontrollers and communication protocols from Microchip and interface components with sensors from Maxim. Temperature and strain measurements have been implemented. Those networks will be available online for implementing new remote experiments which will bring new technology accessible to engineering education and lifelong learning.

Finally, and believing in the deep interest of the "Young Research at University of Porto" program the author has also enthusiastically collaborated in mentoring other new students engaging new annual projects and he is also participating in the elaboration of project proposals.

\section{IN CONCLUSION}

The project based mentoring activities in which the author involved himself on a voluntary base during the first years of his degree were a great help to overcome so many of the freshman problems related with mathematics and conceptual knowledge and turned possible to understand engineering in a much realistic way than by solving only theoretical problems. In relation to the students within the team framework the author became able to understand the differences between team elements (normally in groups of up to 6 elements), how to work as a team by distributing tasks and how to get the better profit from each other. Also, the concept of individual responsibility as a member of the team in charge of one task was perceived. This was also a great opportunity to understand and judge the author's own capabilities and limitations in order to improve his performance and then widen his knowledge and abilities.

All this experience helped to foster the author's maturity, responsibility and knowledge by the reflection process practice, and transferable skills, as those essential to perform or collaborate in ongoing work or final reports in team framework. The author still finds today contributions from all these aspects for his everyday professional integration within R\&D\&I activities. Looking back to all aspects here described it seems to be interesting to compile the transferable skills the author identifies as been strongly improved by project learning mentoring activities described above:

\section{Key Transferable Skills}

- Meet deadlines

- Accept responsibility

- Desire to learn and improve

- Time management

- $\quad$ Solve problems

- Manage costs

- Customer service oriented

- Meet the public

- Team player

- Cooperate in written communications

- Computer skills

- $\quad$ Public Communications

\section{OTHERS}

\section{Dealing with things}

- Follow instructions

- Operate tools 
- $\quad$ Good with my hands

- Construct and repair things

- Assemble or make things

- Safety conscious

- Repair things

- Use lab equipment

- Equipment inventory

\section{Dealing with data}

- Analyze data or facts

- Process data

- Organize databases

- Use investigating methodology

- Classify data

- Locate answers or information

\section{Working with people}

- Meet people

- Be patient

- Respect others

- Confront others

- Demonstrate something

- Present communications

- Work as team member

- $\quad$ Sensitive to the team interests

- Open minded

- Listen

- Self responsibility

- Self assessment

\section{Using Words and Ideas}

- Understand the big picture

- $\quad$ Structure information

- Communicate verbally

- Careful with details

- Design concise information

- Use of IT for ideas \& information communication

- The need to improve written skills

\section{ACKNOWLEDGMENT}

Acknowledgments are due to the University of Porto and to LAETA - Associated Laboratory for Energy, Transport and Aeronautics, to the UISPA research unit and especially to the research team in which the author has been working.

Finally, special thanks are due to the International Society for Engineering Education (IGIP) and to its important initiative "Young Scientist Award" for providing the opportunity to think about all these aspects not yet fully pondered before. It has been an important exercise to understand many features not duly perceived before. It is now clear to the author the relevance of many initiatives globally conducted under University of Porto influence and this increased even more his pride as member of the University of Porto Community.

\section{REFERENCES}

[1] ABET http://www.abet.org/about-abet/

[2] EUR-ACE Framework Standards for the Accreditation of Engineering Programmes, November 17, 2005.

[3] Marques, J.C; Restivo, M.T.; Vieira, M.F.G.; Vaz, M.A.P.; Magalhães, F.D.M.B., A Análise Experimental de Tensões no Contexto de um Caso de Estudo Multidisciplinar, $6^{\circ}$ Congresso Nacional de Mecânica Experimental, July 27-29, 2005, Ponta Delgada, Azores, Portugal.

[4] Jorge Almeida, Pedro Portela, Maria Teresa Restivo and José Couto Marques, Complementary Learning Through Multidisciplinary in Engineering education, Proceedings of WCETE2004, Santos, Brazil.

[5] http://www.esa.int/esaMI/Education/SEMYLB9OY2F_0.html (accessed in June 30, 2012).

[6] D. A. Kolb, Experiential Learning - Experience as the Source of Learning and Development, Prentice-Hall, New Jersey, 1984.

[7] Marques, J. C., Restivo, M. T., Portela, P. and Teixeira, R., Cooperative Teaching Exploring a Multidisciplinary Engineering Problem, IACEE Newsletter, International Association for Continuing Engineering Education, December 2003.

[8] T. Andrade, L. Monteiro, R. Guerra, P. Carvalho, M. R. Quintas, C. M. Silva, T. Amaral, T. Restivo, M.F. Chouzal, J.M. Mendes, C. Sousa: "Development of an Handgrip Dynamometer for Nutricional Assessment", $2^{\text {nd }}$ meeting of young researchers at UP, February 2009.

[9] Tiago Andrade, "Sistema de pesagem para indivíduos com mobilidade diminuída”, Integrated Master Thesis, October 2008, FEUP, Porto, Portugal, http://metalib.fe.up.pt/V/5SX8YS 1FN1HGQHVS8URD62QK58TBFNPSIPIT9G7DLBENRQN624 -17959 ?func $=$ meta- $3 \&$ short-format $=002 \&$ set $\_$number $=280861 \&$ set entry $=000005 \&$ format $=999$

[10] Patent submission PT 105187, pending.

[11] Patent submission PCT/IB2010/055701, pending.

[12] R. Guerra, T. Andrade, E. Marques, M. T. Restivo, T. Amaral, J.M. Mendes, M.F. Chouzal, M. R. Quintas, Carlos Sousa and J. Mota, "Virtual instrumentation for monitoring, digital recording and assessing body composition", $2^{\text {nd }}$ meeting of young researchers at UP, February 2009.

[13] F. Chousal, T. Restivo, M. Quintas, T. Amaral, C. Silva, T. Andrade: "ADIPSMETER, A NEW SKINFOLD CALLIPER SYSTEM”, BIODEVICES 2011, January 26-29, Rome, Italy, 2011.

[14] A. Monteiro, T. Andrade, T. Restivo, M. R. Quintas, C. M. Silva and T. Amaral, "LipoTool - Mechanical design of a new Calliper", $4^{\text {th }}$ meeting of young researchers at UP, 17-18 February 2011.

[15] Tiago Faustino Andrade, Manuel Rodrigues Quintas, Carlos Moreira da Silva, Maria Teresa Restivo, Maria de Fátima Chouzal and Teresa Maria Amaral, "Adipsmeter - wireless communication”, II LAETA Young Researchers Meeting, 10-11 April 2012.

[16] T. F. Andrade, M. R. Quintas, C. M. Silva, M. T. Restivo, M. F. Chouzal and T. M. Amaral, "Virtual Instrumentation for a new Health Care Device”, Proceedings of REV2012 Conference, 4-6 July 2012.

[17] Manuel R. Quintas, Teresa F. Amaral, Tiago F. Andrade, Fátima Chouzal e MariaTeresa Restivo, "LipoTool: Análise do tempo protocolado na medição de pregas cutâneas”, XIV Congresso da APNEP, July 6-7, Lisbon, Portugal, 2012.

[18] Manuel Rodrigues Quintas, Carlos Moreira da Silva, Tiago Andrade, Maria Teresa Restivo, Maria de Fátima Chouzal and Teresa F. Amaral: "Device for measuring skinfold thickness with constant force actuator mechanism, accepted for 15th International Conference on Experimental Mechanics, July 22-27, 2012, Porto, Portugal.

[19] Tiago Faustino Andrade, Manuel Rodrigues Quintas, Carlos Moreira da Silva, Maria Teresa Restivo, Maria de Fátima Chouzal and Teresa Maria Amaral, Wireless Communication Solution for Health Care Equipment, Sensors \& Transducers Journal, Vol. 142, Issue 7, July 2012, pp. 95-104.

[20] T. F. Amaral, T. Restivo, M. R. Quintas, F. Chousal, C. M. Silva, T. F. Andrade, "LipoTool - A new Integrated System for Assessment of Body Composition", accepted by ESPEN 2012, September 6-8, Spain, 2012. 


\section{AUTHOR}

Tiago Andrade is with LAETA - Associate Laboratory for Energy, Transport and Aeronautics and IDMEC-PoloFEUP, Faculdade de Engenharia, Universidade do Porto, Porto, Portugal, tfa@fe.up.pt.

This article is an extended and modified version of a paper presented at the International Conference on Engineering Pedagogy (IGIP2012), held 26 - 28 September 2012, in Villach, Austria. Received 2 January 2013. Published as resubmitted by the authors 27 February 2013. 